\title{
Evidence for acute effects of alcohol and marijuana on color discrimination
}

\author{
ANTHONY J. ADAMS \\ School of Optometry, University of California, Berkeley, California 94720 \\ BRIAN BROWN \\ Smith-Kettlewell Institute of Visual Sciences, San Francisco, California 94115 \\ GUNILLA HAEGERSTROM-PORTNOY \\ Smith-Keitlewell Institute of Visual Sciences, San Francisco, California 94115 \\ MERTON C. FLOM \\ School of Optometry, University of California, Berkeley, California 94720
}

and

REESE T. JONES

Langley Porter Neuropsychiatric Institute, University of California, San Francisco, California 94143

\begin{abstract}
Significant dose-related impairments in hue discrimination on the Farnsworth-Munsell 100 hue test were produced by acute doses of alcohol and marijuana. The impairment of color discrimination was predominantly located in the blue region of the color circle and resembles that seen in acquired color vision defects associated with retinal pathology. The transient nature of the reduced color discrimination raises practical problems in tasks which require stable color perception.
\end{abstract}

Color vision changes have been reported in association with the chronic administration of a variety of drugs used in medical practice (Laroche \& Laroche, 1970, 1972; Siegel \& Arden, 1968). Laroche and Laroche (1972) found that 34 of 56 drugs they studied using the Farnsworth-Munsell 100 hue test decreased color discrimination significantly; the range of drugs included antihistamines, diuretics, anti-inflammatory, antimalarial, antidiabetic, and antibiotic drugs. Alcohol has also been reported to produce changes in color vision with chronic use (Cruz-Coke, 1970; Smith \& Layden, 1971; Swinson, 1972). There are no reports of color vision changes induced by chronic marijuana use.

The increasingly common use of such "recreational" drugs as alcohol and marijuana, has resulted in a heightened interest in the acute effects of these drugs on sensory functions, particularly vision. However, there are very few reports concerning acute vision changes caused by these drugs. The few reports of alcohol-induced acute changes in color vision that exist tend to be characterized by crude color vision testing techniques, little or no statistical treatment of the data, lack of placebo

This rescarch was supported by Contract No. DADA17-73-C3106 from the U. S. Army Medical Research and Development Command to the Visual Sciences Division of the Optical Sciences Group, San Rafael, California, and by National Institute of Health Grants K02MH32904 and DA00033 to R. T. J. The authors wish to thank Richard Balliet and Professor Joseph P. Hegmann for their contributions to this project. conditions, single doses which preclude the establishment of dose relationships, and a disregard for the value of a blind or double-blind experiment. The results are equivocal; there is no general agreement in either the nature or extent of color vision changes. For example. Colson (1940) reported no change in color vision with relatively high alcohol doses on a clinical screening test (the Ishihara pseudoisochromatic plates). Schmidt and Bingel (Note 1) using $60 \mathrm{cc}$ of absolute alcohol found evidence for alcohol-induced reduction of color saturation in all three of their test colors (red, green. and blue), which they attribute to "a deterioration of cerebral functions." Wallgren and Barry (1970) report a study by Rizzo which suggests that after $1.0 \mathrm{ml}$ of alcohol $/ \mathrm{kg}$ body weight, the amount of red in a redgreen mix ture must be increased for most of the subjects io indintain \& match with a standard yellow. We are unaware of any documented studies of the acute effects of marijuana on color vision, only of occasional anecdotal reports by marijuana users.

In view of the nature of previous studies of the acute effects of alcohol on color vision. the lack of studies of effects of marijuana on color vision, and the widespread use of both drugs for recreational purposes, we have conducted a double-blind color discrimination experiment using placebo and two doses of each drug.

\section{METHOD}

The subjects were nine paid volunteers (ages 19 to 28), all of 
Table 1

Means and Standard Deviations of Total Error Scores on Farnsworth-Munsell 100 Hue Test for Nine Subjects, Before and After Drug Ingestion

\begin{tabular}{llccc}
\hline & & \multicolumn{3}{c}{ Time (minutes) } \\
\cline { 3 - 5 } & & $\begin{array}{c}\text { Pre } \\
(-30)\end{array}$ & $\begin{array}{c}\text { Post } \\
(+30)\end{array}$ & $\begin{array}{c}\text { Post } \\
(+90)\end{array}$ \\
\hline \multirow{2}{*}{ Placebo } & Mean & 21.3 & 20.7 & 27.1 \\
& SD & 11.1 & 11.1 & 24.7 \\
$5 \mathrm{ml} / \mathrm{kg}$ & Mean & 17.3 & 21.3 & 21.8 \\
& SD & 11.5 & 15.9 & 14.2 \\
$1.0 \mathrm{ml} / \mathrm{kg}$ & Mean & 23.1 & 36.9 & 32.0 \\
& SD & 14.3 & 17.4 & 22.5 \\
$8 \mathrm{mg} \mathrm{THC}$ & Mean & 22.2 & 26.7 & 25.9 \\
& SD & 11.5 & 17.2 & 26.0 \\
$15 \mathrm{mg} \mathrm{THC}$ & Mean & 23.7 & 35.9 & 24.7 \\
& SD & 20.4 & 27.5 & 16.7 \\
\hline
\end{tabular}

whom were "social drinkers" who had previously smoked marijuana at least five times and were currently smoking 2-5 marijuana cigarettes per week. All subjects were screened for normal color vision using the AO-HRR test. The FarnsworthMunsell 100 hue test (FM 100) was administered three times before any drug treatments to reduce practice effects.

The FM 100 test consists of 85 colored chips selected from the Munsell color circle (Farnsworth, 1943). All chips have the same value (black and white proportion, or lightness) and chroma (saturation, or vividness of color). Each chip consists of a $12-\mathrm{mm}$ colored paper mounted in a black plastic cap. The caps are divided into four sets, each set placed in a separate tray. The first tray contains colors from pink to yellow (caps 85, 1-22); the second, yellow to blue-green (caps 23-42); the third, bluegreen to blue (caps 43-63); and the fourth, blue through purple to pink (caps 64-84). The test was administered and scored using standard procedures outlined in the instructions that accompany the test except that no time limit was imposed on the subject.

The subjects returned for 5 days of testing involving drugs. Two doses of alcohol and two doses of marijuana as well as a double placebo were given to each subject using a balanced Latin square design. In addition to drinking, the subjects smoked a marijuana cigarette each test day. If the subject received an active dose of marijuana, he drank an alcohol placebo; if he was given alcohol, he was given a marijuana placebo. Neither subjects nor experimeters were told which experimental treatment was administered on any test day. The alcohol (95\% USP grade ethanol) was mixed with grapefruit juice and served with two ice cubes in a paper cup, which was covered with a lid. Two drops each of ethanol and eucalyptus oil were placed on the lid to disguise the contents of the drink. The subjects drank the mixture through a straw. The total volume (milliliters) of the drink was always three times the subject's body weight in kilograms, regardless of dose. The doses of alcohol were 0.5 and $1.0 \mathrm{ml} / \mathrm{kg}$ body weight. The $0.8 \mathrm{~g}$ marijuana cigarettes contained $1.4 \%$ and $2.2 \% \Delta^{9}$ te trahydrocannabinol (THC). Cigarettes were smoked leaving a $10-\mathrm{mm}$ butt. This provided doses of approximately 8 and $15 \mathrm{mg}$ THC. Marijuana was supplied by the National Institute on Drug Abuse. Marijuana placebo containing only trace amounts of THC was prepared by the exhaustive solvent extraction of THC from cannabis plant material.

The subjects were tested prior to the drug treatment to establish a baseline for all recorded values including blood alcohol level, pulse rate, and subjective high rating. Subjects were asked to assess their high on a scale of 0 to 100 , where 0 was sober and 100 was the most intoxicated the subject had ever been on either alcohol or marijuana. The blood alcohol level was monitored using the Intoxilizer (Omicron Systems Corporation,
Palo Alto), which estimates blood alcohol level by infrared spectroscopy of a breath sample. The subjects were asked to drink and smoke within $20 \mathrm{~min}$; the marijuana was generally smoked over a 10 -min period and the subjects were encouraged to smoke for "maximum effert." A second experimenter monitored blood alcohol level, pulse rate, and subjective high during the course of the experiment. Tests were performed 30 and $90 \mathrm{~min}$ after the end of the drug ingestion period.

\section{RESULTS}

Error scores were summed for each chip and averaged across subjects. Table 1 shows the mean error score for the test for all treatment conditions and all measurement times. The total number of errors $30 \mathrm{~min}$ after the treatment increases for all drug conditions and dose levels, except placebo, when compared to their respective pretreatment levels; the high doses of alcohol and marijuana produced $60 \%$ and $51 \%$ increases in error scores, respectively. Ninety minutes after the treatment, the initial postdrug increase in errors was reduced slightly for the high-alcohol condition and was essentially back to pretreatment levels for the marijuana. The relatively large drug-induced increase in total error scores at the post-30-min interval was contributed to by seven out of nine subjects for the $1.0-\mathrm{ml} / \mathrm{kg}$ alcohol condition and by 6 out of 9 for the $15-\mathrm{mg}$ THC condition. However, when the postdrug change in error score was compared to the postplacebo change in error score for each subject, the relative increase in error scores failed to reach statistical significance (Walsh test).

The FM 100 test was designed to test for hue discrimination at each of the spectral regions as well as in the nonspectral colors, thus providing information around the entire color circle. Five major color zones are identified in the Munsell system of color specification: yellow, green, blue, purple, and red. When color discrimination is reduced, as in congenital or acquired color vision defects, the reduction is localized in certain regions of the color circle. In order to see if the increased errors were localized in selected regions of the color circle, we examined the error scores produced in each of the Munsell color zones. Again the postdrug change in error score was compared to the postplacebo change in error score in order to eliminate any placebo effects and differences between days. Walsh tests for significance of changes were performed for each color zone. The relative increase in error score in the blue zone is statistically significant $(p<.05)$ for both alcohol $(1.0 \mathrm{ml} / \mathrm{kg})$ and marijuana $(15 \mathrm{mg}$ THC) $30 \mathrm{~min}$ after the treatment. At these same dose levels and at the same time, the increased error scores for the yellow zone for alcohol and the red zone for marijuana are also statistically significant $(p<.02$ and $p<.05$, respectively). Figure 1 shows the conventional representation of 100 hue test error scores around the hue circle; the mean scores for each cap have arbitrarily been multiplied by 10 for illustrative purposes. Both the mean pretreatment scores (average of the five measures made on different 

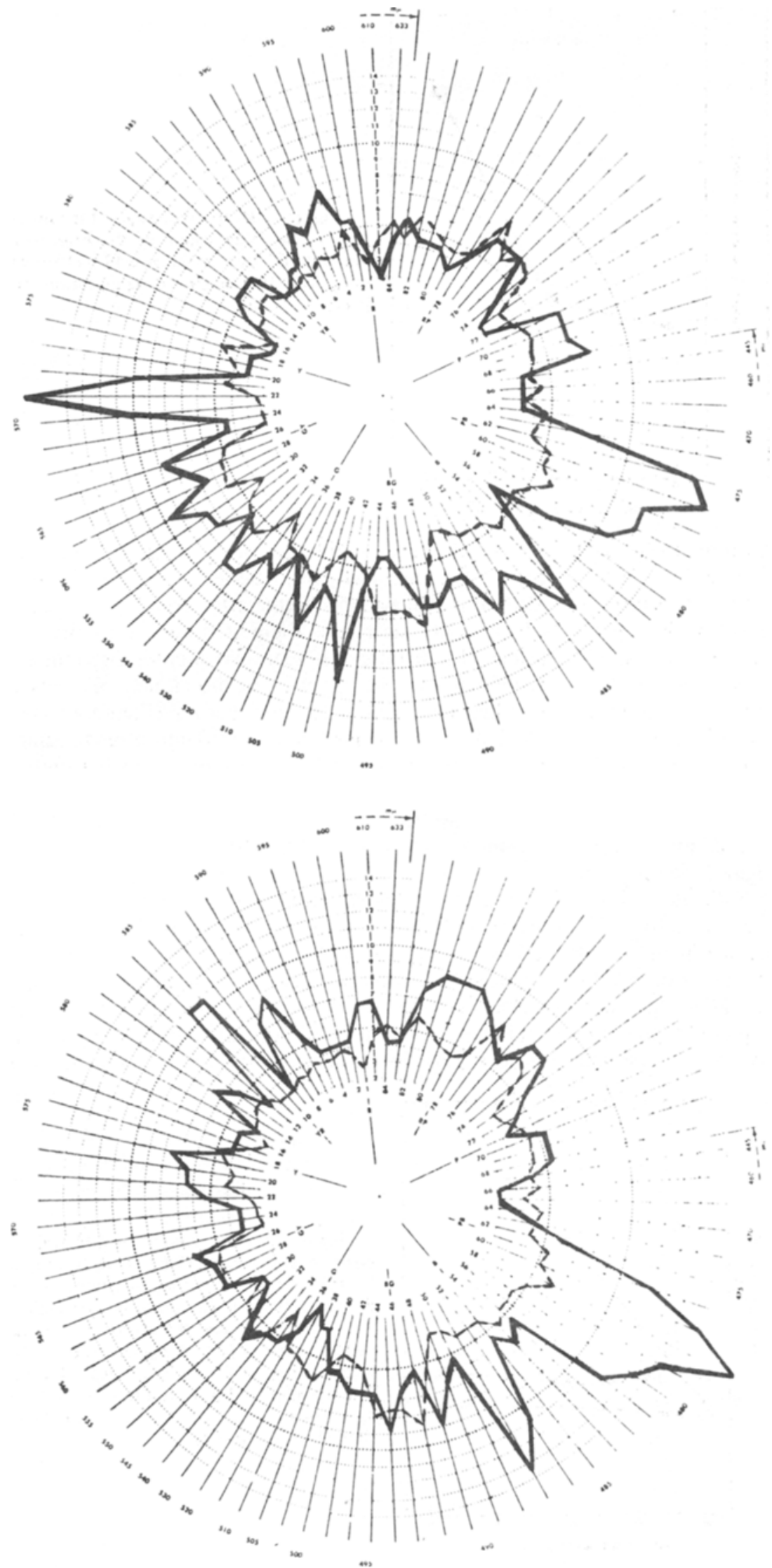

Figure 1. Mean error scores for nine subjects on the Farnsworth-Munsell 100 hue test prior to drug ingestion (light interrupted lines) and $30 \mathrm{~min}$ after drug ingestion (solid heavy lines) of $1.0 \mathrm{ml} / \mathrm{kg}$ ethanol on the top and $15 \mathrm{mg}$ THC on the bottom. The errors are plotted on the conventional polar coordinate score sheet and arbitrarily magnified $10 \times$ to more clearly demonstrate differences around the color circle. 

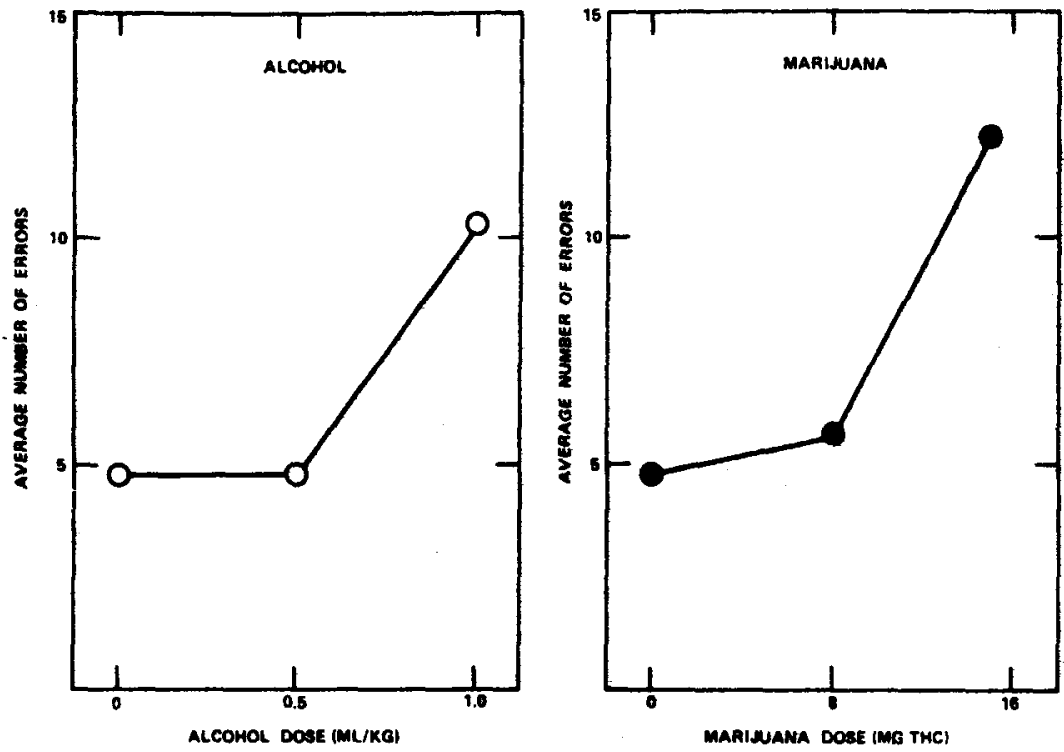

days on each subject) and the posttreatment scores at $30 \mathrm{~min}$ are plotted for the alcohol $(1.0 \mathrm{ml} / \mathrm{kg})$ and the marijuana (15 mg THC) conditions. The nonuniformity of the error score distribution is evident in this figure. For both the alcohol and marijuana conditions, the mean error score is markedly increased in the blue region of the color circle, suggesting a drug induced reduction in discrimination for shades of blue. A less marked loss of color discrimination is evident in the yellow-green is ion for alcohol and in shades of red for marijuana.

The relationship between dose and error scores $30 \mathrm{~min}$ after treatment is shown in Figure 2 for errors in the blue zone (caps 47-61), where both alcohol and marijuana induced a significant increase in errors. The low doses of alcohol $(0.5 \mathrm{ml} / \mathrm{kg})$ and marijuana $(8 \mathrm{mg}$ THC) produce little or no increase in error scores. However, high doses of alcohol $(1.0 \mathrm{mg} / \mathrm{kg})$ and marijuana (15 mg THC) produce more than double the error score of the corresponding placebo treatment. The time course of the drug-induced changes can be seen in Figure 3. The reduced blue discrimination for $1.0 \mathrm{ml} / \mathrm{kg}$ alcohol is still evident $90 \mathrm{~min}$ after drinking, whereas for $15 \mathrm{mg}$ THC marijuana there is a return to presmoke levels. This difference in recovery of color discrimination is reflected in the recovery of blood alcohol levels and marijuana-induced pulse-rate changes (Figure 4): blood alcohol level remained elevated $90 \mathrm{~min}$ after treatment, whereas pulse rate had returned almost to the pretreatment level.

\section{DISCUSSION}

Our results show that hue discrimination, as measured by the FM 100 test, was significantly altered by acute doses of alcohol and marijuana. Moreover, the druginduced reduction in discrimination appears to be greatest in the blue region of the color circle for both alcohol and marijuana: different shades of blue-green or bluepurple may be confused with some blues. A second
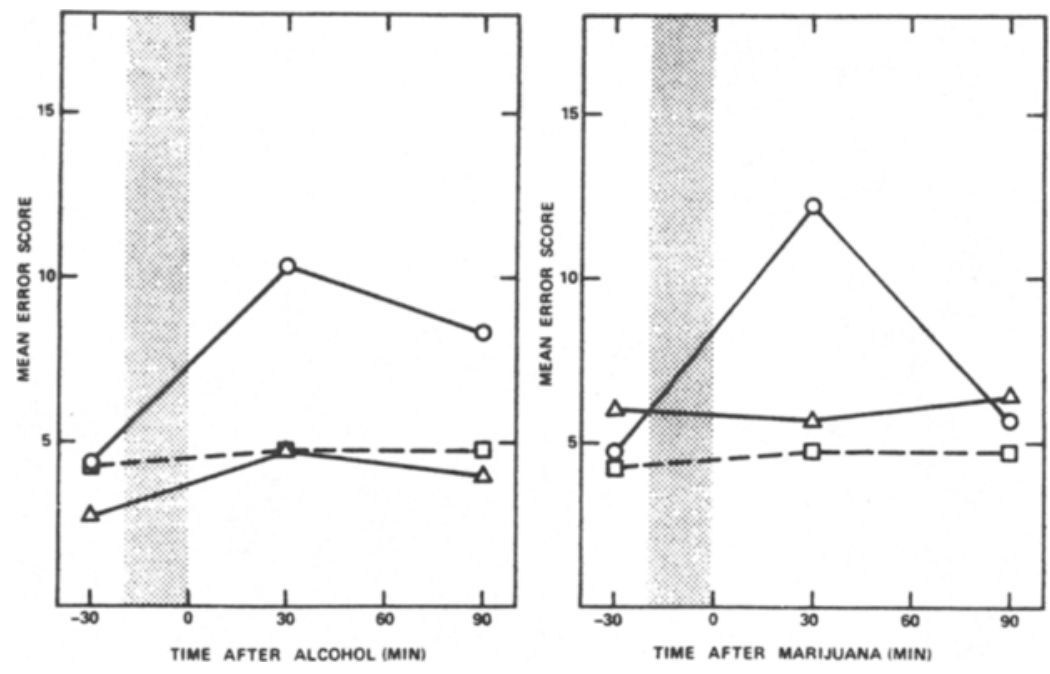

Figure 3. Time course of FM 100 test errors between caps $47-61$ (blue region) for 9 subjects following drug ingestion. Alcohol doses (left) were $1.0 \mathrm{ml} / \mathrm{kg}$ body weight of $95 \%$ ethanol $(0)$ and $0.5 \mathrm{ml} / \mathrm{kg}$ body weight of $95 \%$ ethanol $(\Delta)$. Marijuana doses (right) were $15 \mathrm{mg}$ THC (O) and $8 \mathrm{mg}$ THC $(\Delta)$. The placebo for both conditions is indicated by a square $(\square)$. The shaded area indicates time of drug ingestion. 

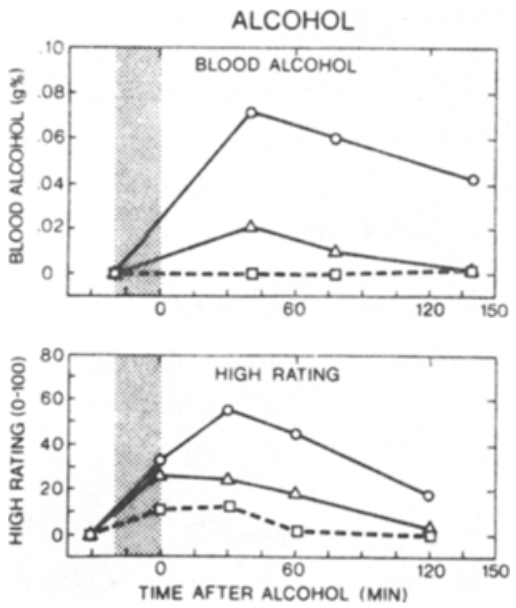
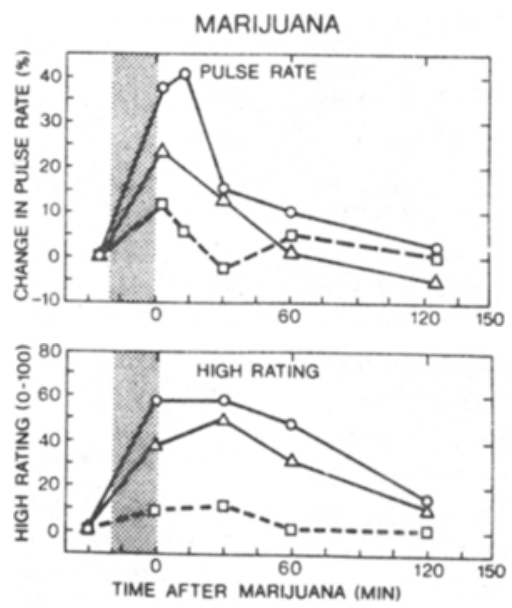

Figure 4. Time course of blood alcohol levels and pulse rate (top panels) and subjects" "high" rating (lower panels). Alcohol doses: $1.0 \mathrm{ml} / \mathrm{kg}$ body weight $95 \%$ ethanol $(c), 0.5 \mathrm{ml} / \mathrm{kg}$ body weight $95 \%$ ethanol $(\Delta)$. Marijuana doses: $15 \mathrm{mg}$ THC (o), $8 \mathrm{mg}$ THC $(\Delta)$. Placebo indicated by 口. The shaded area indicates the time of drug ingestion. region of decreased performance is found in the yellowgreen for alcohol and in the red to yellow-red for marijuana. For an alcohol dose which produces a blood alcohol level of $0.07 \mathrm{~g} \%(0.1 \mathrm{~g} \%$ represents a legal presumption of drunkenness in California), the impairment lasts for at least $1 \frac{1}{2} \mathrm{~h}$ after drinking. The impairment has a much shorter time course for marijuana (15 mg THC), and normal color discrimination returns in less than $1 \frac{1}{2} \mathrm{~h}$ after smoking. These transient changes in color perception are potentially more hazardous than a permanent loss: an unstable color world does not permit the development of the numerous adaptations that individuals with congenital color defects use to minimize the effect of their reduced color discrimination.

In this experiment, as in most discrimination tasks, central factors such as concentration, attention, and motivation were involved, and they too may be affected by marijuana and alcohol and contribute to reduced test performance. By removing the test time constraints which are recommended for this test, we attempted to reduce the influence of central factors. These factors could be expected to produce a general or uniform reduction in test performance at all locations in the color circle. However, our results indicated that this did not occur. Alternatively, it might be argued that a reduction of test aptitude would lead to increased errors in the regions of the test that were most difficult for subjects in the predrug testing rather than producing a uniform increase in errors. The FM 100 test design goal, to provide equal just-noticeable hue differences around the color circle for color normals, was not achieved (Kinnear, 1970; Verriest, 1963). Using 94 color-normal observers, Verriest (1963) showed that more errors are made in some regions of the test than in others. Our subjects found the test most difficult in the region between caps 42 and 50 prior to drug treatment, as did Verriest's nondrug subjects (Figure 5), yet our subjects make significant drug-induced errors between caps 47 and 61 (Munsell Blue zone). Nevertheless, to test the hypothesis that a general loss in test aptitude would lead to reduced performance in the most difficult test regions, we calculated an index of difficulty for each cap position from the group error scores in predrug trials. Postdrug error scores were then weighted by this index. Even after correcting for nonuniformities in test difficulty, our subjects show the same regional losses in color performance, suggesting that the drugs produced an impairment specific to color discrimination and not simply a general loss of test aptitude.

Congenital color vision defects lead to characteristic

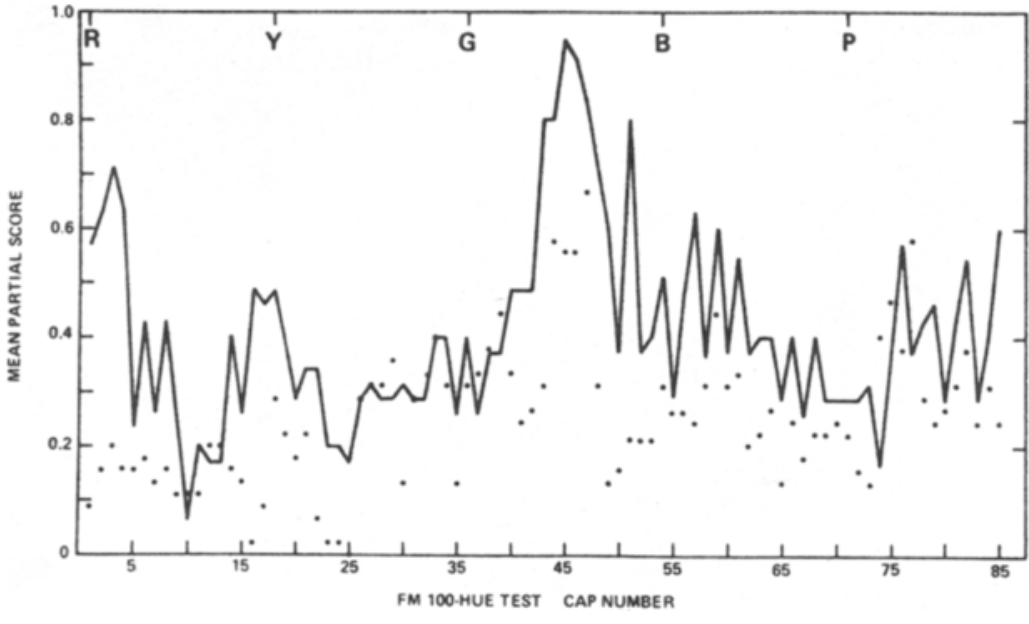

Figure 5. Mean partial error score (i.e., mean error score for each cap location) on the Farnsworth-Munsell 100 hue test. Solid line indicates results of Verriest (1963) for 94 subjects (60 males and 34 females) between the ages of 20 and 24. Dots indicate the predrug results for nine subjects in our study, each subject measured five times. The corresponding zones of the color circle are indicated at the top of the figure. The mean total error score for our nine subjects is lower than that reported by Verriest. This is probably due to the fact that our subjects had no time constraint for the test and had three practice sessions prior to testing. 
losses of color discrimination in well defined regions of the FM 100 hue test. The errors accumulate in the areas of yellow-red to yellow and blue to purplish-blue in the case of the deutan defect, in the yellow-green to yellow and bluish-purple to purple areas in the case of a protan defect, and in the red and blue-green areas for tritan defects. Each congenital form of color-defective vision results from either the loss of a cone pigment (for dichromats) or a modification of the pigment action spectrum (for anomalous trichromats). Acquired color vision defects, usually the consequence of retinal disease, mimic the congenital defects in many ways. However, the areas of color confusion are often wider or displaced compared to the congenital counterpart; sometimes the acquired color defect resembles a combination of the three types of congenital defect (Francois \& Verriest, 1961). While the retinal location of the defect is easily determined, the mechanism and exact location in the retina has not been established. Koellner's "law" provides a relatively crude but useful distinction between lesions in the outer layers of the retina which tend to produce tritan-like defects, while lesions of the inner layers of the retina and optic nerve tend to be associated with protan or deutan-like defects. The changes that we have seen with alcohol and marijuana are similar to those seen in mild acquired color-vision disorders. The druginduced areas of color confusion resemble a combination of deutan and tritan defects, particularly in the blue region of the color circle. Since these acquired defects are usually of retinal origin and alcohol is known to produce direct effects on retinal function (Ikeda, 1963), it may be that the impaired color discrimination seen in our experiments is a result of the direct action of alcohol and marijuana on the retina.

In summary, we have shown a statistically significant impairment in color discrimination on the FM 100 hue test following alcohol or marijuana intoxication. The impairment is predominantly localized in the blue region of the color circle, although alcohol produces an additional impairment in the yellow-green, and marijuana in the yellow-red, region. The regions of reduced color discrimination resemble those seen in acquired color vision defects associated with retinal disease, which leads us to speculate that the site of the drug effect may also be retinal. The transient impairment, which cannot be explained by a general drug-induced loss of test aptitude, may have practical implications in tasks where stable color perception is important.

\section{REFERENCE NOTE}

1. Schmidt, I., \& Bingel, A. G. A. Effect of oxygen deficiency and various other factors on color satunation thresholds. USAF School of Aviation Medicine Project Reports, 1953. Project No. 21-31-002.

\section{REFERENCES}

Colson, Z. W. The effect of alcohol on vision. Journal of the American Medical Association, 1940, 115, 1525-1527.

CRUz-COKe, R. Color blindness. An evolutionary approach. Springfield: Thomas. 1970.

Farnsworth, D. The Farnsworth-Munsell 100-hue and dichotomous tests for color vision. Joumal of the Optical Society of America, 1943, 33, 568-578.

Francois, J., \& VerRiest, G. On acquired deficiency of colour vision. with special reference to its detection and classitication by means of the tests of Farnsworth. Vision Reseanch, 1\%1, 1. 201-219.

IKEDA. H. Effects of ethyl alcohol on the evoked potential of the human eye. Vision Reseanch, 1963, 3, 155-169.

Kinnear, P. R. Proposals for scoring and assessing the 100-hue test. Vision Research, 1970, 10, 423-433.

Laroche, J., \& Laroche. C. Action de quelque antibiotiques sur la vision des couleurs. Annales Pharmaceutiques Francaises. 1970. 28. 333-341.

LAROCHE. I., \& LAROChE. C. Modifications de la vision des couleurs apportees par l'usage, à dose thérapeutique normale, de quelque médicaments. Annales Pharmaceutiques Francaises, 1972, 30. 433-444.

Siegel. I. M.. \& ARden. G. B. The effects of drugs on colour vision. In A. Herxheimer (Ed.), Drugs and sensory functions. Boston: Brown, 1968. Pp. 210-228.

Smith J. W.. \& Layden. T. A. Color vision defects in alcoholism-II. British Journal of Addiction, 1971, 66 , 31-37.

Swinson, R. P. Colour vision defects in alcoholism. British Journal of Physiological Optics. 1972, 27, 43-50.

VERRIEST, G. Further studies on acquired deficiency of color discrimination. Journal of the Optical Society of America, $1963,53,185-195$.

Wallgren, H., \& BARRy, H. Actions of Alcohol (Vol. I). Amsterdam: Elsevier, 1970. Pp. 287-295.

(Received for publication December 1, 1975; revision accepted March 22, 1976.) 